\title{
As percepções de professores supervisores e alunos bolsistas do PIBID sobre a introdução do pensamento computacional por meio de atividades desplugadas
}

\author{
Perceptions of supervising teachers and scholarship students of PIBID on the introduction of \\ computational thinking through unplugged activities in basic education
}

Percepciones de maestros supervisores y estudiantes PIBID sobre la introducción del pensamiento computacional a través de actividades desenchufadas

Recebido: 28/09/2021 | Revisado: 04/10/2021 | Aceito: 05/10/2021 | Publicado: 09/10/2021

\author{
Hadassa de Oliveira Gomes Gabillaud \\ ORCID: https://orcid.org/0000-0002-5201-184X \\ Universidade Pitágoras Unopar, Brasil \\ E-mail: hadassa.gomes@gmail.com \\ Eliza Adriana Sheuer Nantes \\ ORCID: https://orcid.org/0000-0003-3260-7264 \\ Universidade Pitágoras Unopar, Brasil \\ E-mail: elizanantes@gmail.com
}

\begin{abstract}
Resumo
Este trabalho objetivou verificar as percepções dos participantes da pesquisa quanto à viabilidade e o nível de dificuldade encontrado em relação à introdução do pensamento computacional (PC) na educação básica, por meio da realização de atividades desplugadas. Para isso, os participantes da pesquisa, alunos de Pedagogia, bolsistas do programa PIBID, e as professoras supervisoras, receberam uma capacitação sobre os pilares do pensamento computacional (decomposição, reconhecimento de padrões, abstração e algoritmos) e além disso realizaram cinco atividades desplugadas que posteriormente poderiam aplicá-las junto aos alunos das escolas em que atuam. Metodologicamente, procedeu-se a uma pesquisa qualitativa, baseada na coleta de dados por meio do instrumento questionário, em consonância com aspectos metodológicos da Análise de Conteúdo proposta por (Bardin, 2016). A (BNCC) Base Nacional Comum Curricular (BRASIL, 2017), prevê o uso dos conceitos do PC para auxiliar os processos de resolução de problemas, o que demonstra a importância do presente estudo. A presente pesquisa, contribui para a formação docente ao subsidiar a prática metodológica do professor supervisor e do licenciando bolsista PIBID. O resultado da aplicação das atividades realizadas pelas professoras supervisoras, com o auxílio dos bolsistas, apontou para a efetividade do trabalho com o PC na escola.
\end{abstract}

Palavras-chave: Ensino; Pensamento computacional; PIBID; Atividades desplugadas.

\begin{abstract}
This study aimed to verify the research participants' perceptions regarding the feasibility and the perceived difficulty level of difficulty found in relation to the introduction of computational thinking (CT) in basic education, through the performance of unplugged activities. For this, the research participants, Pedagogy students, PIBID scholarship holders, and the supervising teachers, received training to know the pillars of computational thinking (decomposition, pattern recognition, abstraction and algorithms). In addition, they performed five unplugged activities, which they could apply to their students in the schools where they work. Methodologically, qualitative research was performed, based on data collection through the questionnaire instrument, aligned with methodological aspects of the Content Analysis proposed by (Bardin, 2016). The (BNCC) Common National Curriculum Base (BRASIL, 2017), foresees the use of the concepts of the CT to help the problem-solving processes, which shows the importance of the present study. This research contributes to teacher training by subsidizing the methodological practice of the supervising professor and the PIBID scholarship holder. The result of the application of the activities performed by the supervising teachers, with the help of the scholarship students, demonstrated the effectiveness of the work with the CT at school.
\end{abstract}

Keywords: Teaching; Computation thinking; PIBID; Unplugged activities.

\section{Resumen}

Este estudio tuvo como objetivo verificar las percepciones de los participantes de la investigación sobre la viabilidad y el nivel de dificultad encontrado en relación a la introducción del pensamiento computacional (PC) en la educación básica, a través de la realización de actividades desenchufadas. Para ello, los participantes de la investigación, estudiantes de Pedagogía, becarios PIBID y docentes supervisores recibieron capacitación sobre los pilares del pensamiento computacional (descomposición, reconocimiento de patrones, abstracción y algoritmos) y también realizaron cinco actividades desenchufadas que luego podrían aplicarlas a estudiantes de las escuelas en las que 
trabajan. Metodológicamente, se realizó una investigación cualitativa, basada en la recolección de datos a través del instrumento cuestionario, en línea con los aspectos metodológicos del Análisis de Contenido propuesto por (Bardin, 2016). La Base Nacional Común Curricular (BNCC) (BRASIL, 2017) prevé el uso de conceptos de PC para ayudar en los procesos de resolución de problemas, lo que demuestra la importancia de este estudio. La presente investigación contribuye a la formación docente al subsidiar la práctica metodológica del maestro supervisor y del estudiante de posgrado con una beca PIBID. El resultado de la aplicación de las actividades realizadas por los docentes supervisores, con la asistencia de los becarios, señaló la efectividad del trabajo con el PC en la escuela.

Palabras-clave: Enseñando; Pensamiento computacional; PIBID; Actividades desenchufadas.

\section{Introdução}

Os termos "gig economy" e "uberização" emergem de uma nova forma de gestão, organização e controle do trabalho, seguindo uma tendência mundial mediada pelas plataformas digitais que estabelece novas relações de trabalho, conforme explica (Abilio, 2019). Esse processo “consolida o trabalhador como um autogerente-subordinado que já não é contratado, mas se engaja no trabalho via a adesão às plataformas" (Abilio, 2019, p. 2).

Algo que havia sido preconizado por (Costa, 2010), ao afirmar que as transformações tecnológicas trazem incertezas ao mundo do trabalho, pois se antes as pessoas se dedicavam exclusivamente a uma única organização ou a uma carreira, as novas configurações de trabalho abrem possibilidades e, ao mesmo tempo, exigem profissionais qualificados e preparados para enfrentar os desafios que a era digital impõe.

Essas transformações também são observadas na escola contemporânea. Com isso, evidenciamos um apelo crescente para que sejam desenvolvidas, nas crianças e jovens, as competências para lidar com as demandas do Século XXI. Assim, em virtude das novas tecnologias, também é possível que haja alteração na carreira do professor e em seu processo de formação, levando-nos a refletir sobre como as tecnologias podem contribuir para a prática docente.

Desse modo, dentre os caminhos possíveis para subsidiar a prática pedagógica do professor da educação básica, a inserção de atividades que contemplem os conceitos da computação surge como um instrumento capaz de desenvolver nos alunos o pensamento computacional, definido, de modo introdutório, como saber usar o computador como instrumento de aumento do poder cognitivo e operacional humano, aumentando a produtividade, a inventividade e a criatividade (França, et al., 2012).

Assim, a necessidade desta pesquisa se justifica em face das novas perspectivas na área do Ensino pois, de acordo com (Garlet, et al., 2016), no meio em que vivemos não devemos ser apenas consumidores de tecnologia, mas também produtores. A problemática se estabelece quando o processo de formação do professor não o prepara para que se sinta apto na exploração do uso e ensino de tecnologia.

Sendo assim, este artigo consiste em um relato de experiência acerca da introdução do pensamento computacional por meio de atividades desplugadas na educação básica, após os professores supervisores e os alunos bolsistas do PIBID, do município de Londrina-PR, terem acesso aos pressupostos teóricos do pensamento computacional.

\section{Referencial Teórico}

O termo "pensamento computacional”, ou computation thinking, foi difundido pela pesquisadora Jeannette M. Wing, após a publicação de um artigo intitulado “Computational Thinking” em 2006. De acordo com a autora, o "pensamento computacional se baseia no poder e nos limites de processos de computação, quer eles sejam executados por um ser humano ou por uma máquina" (Wing, 2006, p. 2).

Desde então, o termo Pensamento Computacional foi disseminado pelo mundo acadêmico. Hoje, encontramos diversas publicações, fruto de pesquisas que propõem averiguar a importância do desenvolvimento do PC. Apesar de não ter criado o termo, o autor (Brackmann, 2017) afirma que ela foi a responsável pela sua popularização. 
A autora (Wing, 2006) assevera que o PC é uma habilidade necessária não apenas para cientistas da computação, mas que todos devem se apropriar dela, e complementa que, ao conjunto da leitura, da escrita e da aritmética, deveríamos adicionar o PC na habilidade analítica de todas as crianças.

A autora afirma que os "métodos e modelos computacionais nos dão a coragem para resolver problemas e projetar sistemas que nenhum de nós seria capaz de enfrentar sozinhos" (Wing, 2006, p. 2). Para trazer um claro entendimento sobre como isso ocorre, a autora faz diversas explanações sobre o tema. Primeiramente, (Wing, 2006, p. 2) explica que o PC "[...] baseia-se no poder e limites de processos computacionais, sejam eles executados por um humano ou por uma máquina". Ademais, o PC “[...] confronta o enigma da inteligência da máquina: $\mathrm{O}$ que humanos fazem melhor que computadores? $\mathrm{E}$ o que computadores fazem melhor que humanos?"

(Wing, 2006) também estabelece uma relação entre o PC e a resolução de problemas:“[...] envolve a resolução de problemas, projeção de sistemas, e compreensão do comportamento humano, através da extração de conceitos fundamentais da Ciência da Computação", já que, “[...] ao tentar solucionar um problema, a Ciência da Computação se apoia em fundamentos teóricos sólidos para responder perguntas com precisão" (Wing, 2006, p. 2).

Outro aspecto ressaltado é que "o pensamento computacional é [capaz de] reformular um problema aparentemente difícil em um problema que sabemos como resolver, talvez por redução, incorporação, transformação ou simulação" (Wing, 2006, p. 2). Para autora, o PC consiste na questão: O que é computável? E se apoia nos conceitos fundamentais da Ciência da Computação após analisar o quão difícil é resolver determinado problema e averiguar a melhor forma de solucioná-lo. E complementa afirmando que o PC trata-se de uma habilidade fundamental, não mecânica; por ser fundamental, explica que todos devem se apropriar dela para atuar na sociedade moderna (Wing, 2006, p. 4).

Na sequência, a pesquisadora passa a esclarecer o que o PC não é: "uma forma que humanos, não computadores, pensam" (Wing, 2006, p. 4). Outro excerto aponta que também “[...] não é tentar fazer com que seres humanos pensem como computadores" (Wing, 2006, p. 4).

(Wing, 2006) defende que professores de Ciência da Computação deveriam lecionar nas universidades uma disciplina chamada "formas de pensar como um Cientista da Computação", não apenas para os alunos de Ciência da Computação, mas buscando formas de inspirar o interesse de outros alunos e fazendo do PC um lugar comum.

O artigo de (Wing 2006) inspirou outros pesquisadores, que vieram a campo buscando não apenas disseminar os conceitos de pensamento computacional, mas também para comprovar sua importância e aplicabilidade, por meio de diversas pesquisas acadêmicas.

Uma importante publicação, que serve como base para entender os conceitos do PC, é o artigo do professor e pesquisador Paulo Blikstein, publicado em 2008, intitulado "O pensamento computacional e a reinvenção do computador na educação".

Nele, (Blikstein, 2008) afirma que as inúmeras pesquisas que discutem o ensino na educação básica são válidas e acumulam uma grande quantidade de publicações e análises detalhadas sobre o desempenho dos estudantes e sobre a alfabetização de crianças. Porém, o atual contexto em que vivemos exige outras habilidades, e uma das mais importantes, porém menos compreendida, é o PC.

Dando prosseguimento sobre a questão das habilidades, o autor pontua que a "[...] lista de habilidades e conhecimentos necessários para o pleno exercício da cidadania no século XXI é tão extensa quanto controversa. Não sabemos muito bem quais são essas habilidades, muito menos como ensiná-las" (Blikstein, 2008).

Tal como (Wing, 2006), (Blikstein, 2008) também esclarece o que PC não é, destacando questões como: não é saber navegar na internet, enviar e-mail, utilizar os processadores de texto, ou fazer publicações em blogs, mas é utilizar o computador "[...] como um instrumento de aumento do poder cognitivo e operacional humano". Ou seja, aumentar a 
produtividade, a inventividade e a criatividade com o auxílio de um computador e das redes de computadores.

Para (Blikstein, 2008), o PC está causando transformações, não apenas na academia, mas também na indústria. Desde um cientista em um laboratório de pesquisa, a um engenheiro industrial, ou um economista, todos utilizam modelos computacionais. $\mathrm{O}$ autor enfatiza:

A primeira etapa do "pensar computacionalmente" é identificar as tarefas cognitivas que podem ser feitas de forma mais rápida e eficiente por um computador. A segunda etapa é saber programar um computador para realizar essas tarefas cognitivas - em outras palavras, transferir aquilo que não é essencialmente humano para um computador que, como sabemos, é bem burrinho, mas muito rápido (Blikstein, 2008).

O principal erro das escolas, apontado pelo autor, é que os alunos recebem "adestramento digital", enquanto deveriam aprender que a tecnologia serve para criar novos conhecimentos, e não reproduzir informações já existentes. Os alunos não devem se acomodar com as informações de fácil acesso dos mecanismos de busca, mas "viver em simbiose cognitiva com as máquinas e suas redes".

Para (Blikstein, 2008), as pesquisas têm comprovado que os alunos aprendem ciência computacional mais facilmente que a ciência tradicional, pelos fatores cognitivos, epistemológicos e motivacionais, pois muitas das teorias ensinadas hoje nas escolas foram desenvolvidas antes de os computadores serem criados, tornando o aprendizado mais difícil.

(Blikstein, 2008), conclui que ensinar PC para as crianças não se trata de fazê-las menos humanas; é justamente o contrário, uma vez que, ao longo da história, o homem sempre buscou livrar-se de tarefas repetitivas e focar no mundo das ideias. É disso que o PC trata, transformar teorias, hipóteses em modelos e programas para o computador, e com isso nos tornamos mais dependentes dele e, paradoxalmente, diferentes dele. Esse é justamente o desafio dos educadores que desejam repensar a tecnologia na sala de aula, unir esforços para que as crianças entendam esse paradoxo, sejam mais produtivas e criativas e, ao mesmo tempo, dependentes das máquinas.

Recentemente (Raabe, et al., 2020), classificaram as diversas abordagens que surgiram para o ensino de Ciência de Computação. Cada uma se constituiu a partir de visões de pesquisadores da academia.

Cada abordagem carrega um conjunto de valores, crenças e objetivos que influenciam significativamente a forma como compreende o papel da computação na sociedade e em como deve ser inserida na educação básica. (Blikstein, 2018) recomenda que se crie clareza e alinhamento em torno das principais razões que as diversas partes interessadas usam para promover a computação na educação, destacando suas sinergias, diferenças e consequências para o ensino em sala de aula (Raabe, et al., 2020, p. 3).

Sendo assim, os autores classificam em quatro abordagens os movimentos da computação na educação básica. A primeira, "construcionismo e letramento computacional", vem de uma cultura educacional, pois está atrelada às ideias defendidas por Seymour Papert, quando propôs a Linguagem Logo e fundamentou o Construcionismo, que trata o computador como uma máquina a ser ensinada, em um processo no qual o estudante é protagonista da aprendizagem, construindo objetos concretos e compartilháveis que sejam de seu interesse, desenvolvendo, assim, sua autonomia e criatividade. O letramento computacional, por sua vez, faz parte dos estudos de (diSessa, 2001), que cunhou o termo referindo-se aos computadores como "[...] a base técnica de um novo tipo de letramento" (Raabe, et al., 2020, p. 4).

A segunda abordagem, "a emergência do Pensamento Computacional", vem de uma cultura computacional, defendida por cientistas da computação, e se consolidou com a publicação de (Wing, 2006), quando propôs que a forma como os cientistas da computação pensam e suas estratégias para resolução de problemas, “[...] deveriam ser aplicadas não só à solução de problemas computacionais, mas também a outras disciplinas e à vida cotidiana" (Raabe, et al., 2020, p. 6).

Ainda segundo os autores, na terceira abordagem, "code.org e a demanda de mercado", surgem as iniciativas de ONGs e empresas de tecnologia que tratam o ensino de computação como oportunidade de carreira e trabalho para jovens. 
Essa abordagem é a mais criticada por acadêmicos e educadores, pois ela vem de uma cultura de mercado de empresas de tecnologia.

(Raabe et al., 2015) também afirmam que é preciso desmistificar essa ideia de que o PC trata apenas de aprender a codificar computadores. Para os autores, algumas iniciativas, como as da terceira abordagem, têm justificado o ensino de programação como um argumento para preencher vagas de trabalho, na área de tecnologia, que apresenta uma alta demanda profissional, mas, para eles, encarar o PC dessa forma é uma visão muito limitada.

$\mathrm{Na}$ quarta abordagem, "equidade e inclusão", surgem iniciativas buscando dar as mesmas oportunidades a todos os cidadãos, pois em um mundo permeado por tecnologia e computação é imprescindível conhecimentos para que todos exerçam sua cidadania de forma integral, e estejam aptos a lidar com tecnologia, não apenas como meros usuários, mas, também, como produtores.

Corroboramos com o entendimento de (Raabe, et al., 2020), no que tange ao fato de as abordagens virem de diferentes culturas e trazerem seus valores e preceitos. Entretanto, em alguns momentos, elas se aproximam e trazem benefícios quanto à introdução do PC na educação básica. Como, por exemplo, podemos citar que todas utilizam o termo pensamento computacional, contudo, cada uma traz seu enfoque, porém convergem para a ideia de que a programação e as habilidades cognitivas que estão relacionadas ao desenvolvimento de algoritmos voltados para a solução de problemas, são habilidades que todas as pessoas precisarão se valer em um determinado momento.

É válido destacar que, conforme explica (Brackmann, 2017), ao se referir às iniciativas brasileiras quanto à adoção do PC na educação básica, "[...] as políticas educacionais relacionadas à tecnologia estão restritas à abordagem de letramento e inclusão digital" (Brackmann, 2017, p. 99).

Assim, desde 2015, quando se iniciou a construção da BNCC, a SBC (Sociedade Brasileira de Computação) está engajada na introdução do pensamento computacional, buscando alinhar os currículos de licenciatura em computação com a BNCC.

Para isso, a SBC tem elaborado materiais para conscientização e divulgação. Esses documentos propõem competências a serem trabalhadas com estudantes e foram entregues ao MEC, pois a versão inicial da BNCC não fazia referência à área de computação, apresentando apenas as Tecnologias Digitais como tema integrador. Sendo assim, a SBC propôs modificações no teor da BNCC, para que a computação fosse considerada uma área de conhecimento.

Entretanto, o uso dos conceitos do PC ainda está previsto na BNCC apenas nas disciplinas de matemática para o ensino fundamental, para auxiliar os processos de resolução de problemas (BRASIL, 2017). Nesse sentido, concordamos que deve-se trabalhar o PC nas escolas de forma interdisciplinar, o que significa trabalhar os conceitos da Ciência da Computação relacionados aos conceitos de outras disciplinas. Para isso é necessário manter uma comunicação constante entre universidade e comunidade escolar.

Uma forma de trabalhar essa interdisciplinaridade é disseminar os fundamentos do PC entre professores em formação de cursos de licenciatura, com o objetivo de incentivar ações em suas áreas de atuação.

\section{Metodologia}

A metodologia de pesquisa mobilizada caracteriza-se como qualitativa, que, conforme explica (Minayo, 2002, p. 21), "responde a questões muito particulares [...] ela se preocupa nas ciências sociais, com um nível de realidade que não pode ser quantificado". A pesquisa teve, a partir disso, uma abordagem descritiva e analítica.

De acordo com (Gil, 2002, p.42), as "pesquisas descritivas têm como objetivo primordial a descrição das características de determinada população ou fenômeno ou, então, o estabelecimento de relações entre variáveis". E a finalidade da leitura analítica é "ordenar e sumariar as informações contidas nas fontes, de forma que estas possibilitem a obtenção de 
respostas ao problema da pesquisa" (Gil, 2002, p. 78).

O lócus da pesquisa, é o subprojeto "Letramentos e diversidade no contexto escolar", que faz parte do projeto institucional "Formação docente, letramento e diversidade", desenvolvido pela UNOPAR e vinculado ao Programa Institucional de Bolsa de Iniciação à Docência (PIBID).

A fim de promover contribuições para a formação inicial de seus alunos licenciandos e construir referenciais teóricos e práticos para atuação docente, a UNOPAR elaborou um projeto, intitulado "Formação docente, letramento e diversidade", e o inscreveu no PIBID, criado em 2007 pela Coordenação de Aperfeiçoamento de Pessoal de Nível Superior (CAPES) e regulamentado mais detalhadamente pelo Decreto n. ${ }^{\circ}$ 7219/2010 (BRASIL, 2010).

O Edital de Seleção ofertou 30 bolsas para alunos do curso de Educação Física e 32 bolsas para o curso de Pedagogia. Enquanto o Edital de Seleção para Professores Supervisores, disponibilizou nove bolsas, para docentes das áreas contempladas. O projeto em epígrafe subdividiu-se em 3 núcleos que estão sintetizados na Figura 1, a seguir: 
Figura 1 - Organização do PIBID na UNOPAR.

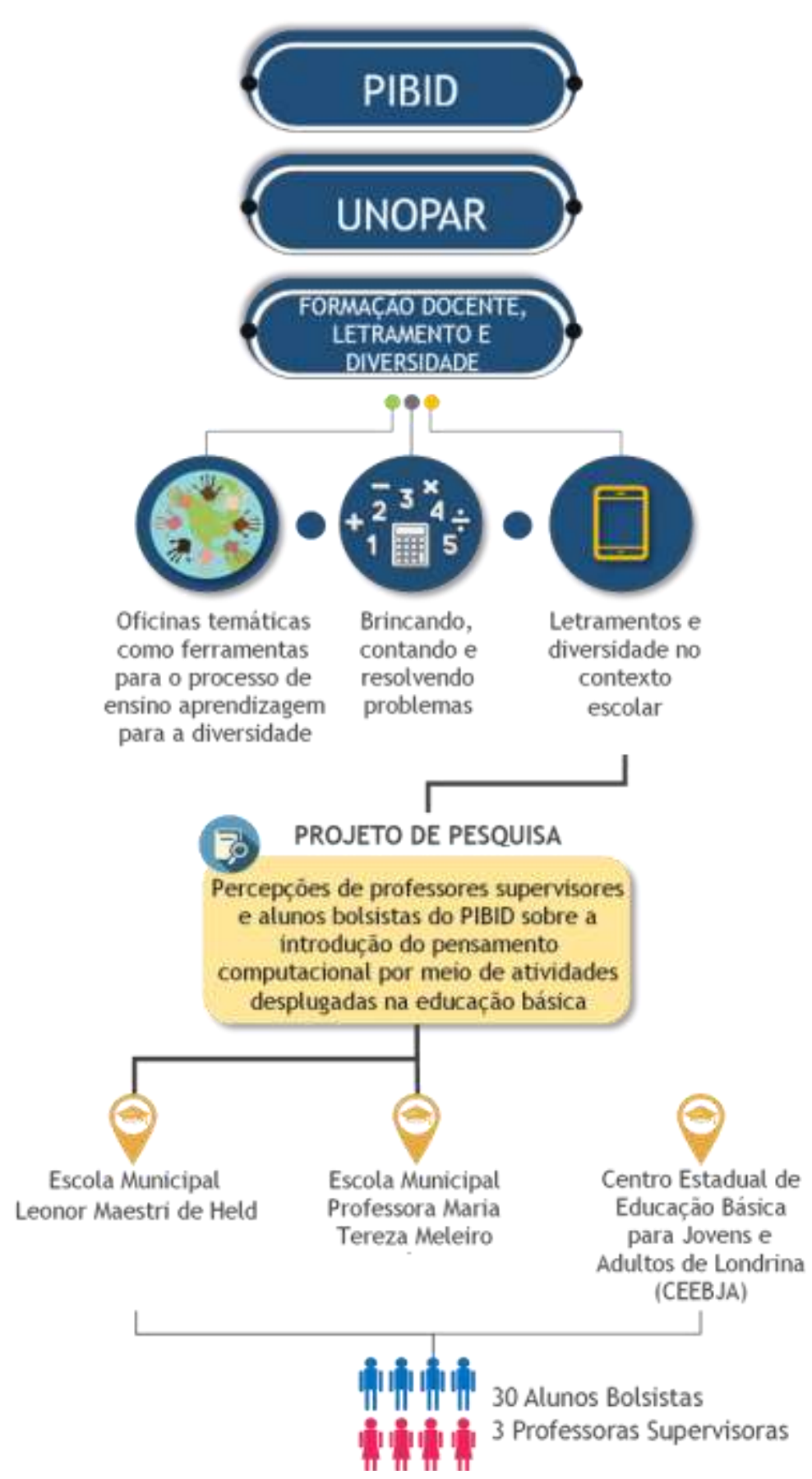

Fonte: Autores.

Conforme evidencia a Figura 1, a pesquisa está vinculada ao subprojeto "Letramentos e diversidade no contexto escolar", e o referido núcleo possui parceria com três escolas de Londrina-PR: Escola Municipal Leonor Maestri de Held; Escola Municipal Professora Maria Tereza Meleiro Amâncio; e Centro Estadual de Educação Básica para Jovens e Adultos de Londrina (CEEBJA). Em cada escola, está alocada uma professora supervisora com seus alunos bolsistas, porém somente as escolas municipais participaram da pesquisa.

No que concerne à seleção dos participantes da pesquisa, o público-alvo foi selecionado em função da intersecção entre o projeto de pesquisa de que participamos e o programa de pós-graduação que as pesquisadoras integram. Isso possibilitou o contato com os participantes da pesquisa, por meio das reuniões mensais a que eles deveriam comparecer. 
Quanto ao critério de inclusão, optou-se pelos discentes e pelas professoras que atuam com turmas de $2^{\circ}$ e $3^{\circ}$ ano nas Escolas Municipais Leonor Maestri de Held e Professora Maria Tereza Meleiro Amâncio, pois o foco da pesquisa é a educação básica.

Os dados da pesquisa foram coletados via questionário, instrumento com respaldo nas pesquisas de (Gil, 2002), tendo em vista que o autor assevera que "a elaboração de um questionário consiste basicamente em traduzir os objetivos específicos da pesquisa em itens bem redigidos", destacando que "o questionário constitui o meio mais rápido e barato de obtenção de informações, além de não exigir treinamento pessoal e garantir o anonimato" (Gil, 2002, p. 115 -116).

Assim, foram elaborados dois questionários, aplicados por meio da plataforma digital Google Forms.

Questionário 1: aplicado após a realização das atividades desplugadas pelos alunos bolsistas e professoras supervisoras, sob orientação das pesquisadoras - setembro (2019).

Questionário 2: aplicado após a realização das atividades desplugadas pelos alunos da educação básica, sob orientação das professoras supervisoras, com o auxílio dos alunos bolsistas - outubro a dezembro (2019).

Quanto aos passos para a coletado dos dados, foram organizadas cinco atividades extraídas do site (http://www.computacional.com.br) elaboradas por (Brackmann, 2017), que contemplam a abordagem desplugada e que foram desenvolvidas para a mesma faixa etária indicada pelas professoras supervisoras.

Após a realização das atividades "Decomposição", "Caminhos", "Bugs", "Boneca de Papel" e "Cupcakes", foi aplicado um questionário, com o objetivo de verificar as percepções dos participantes da pesquisa quanto à realização das atividades e ao nível de dificuldade encontrado, além da viabilidade da realização das atividades juntamente aos alunos das escolas em que atuam.

Anteriormente a aplicação das atividades, os participantes assistiram a uma apresentação denominada "Pensamento Computacional para Professores" para contextualização do tema, e, na sequência, as pesquisadoras procederam à realização das atividades explicando-se cada etapa.

A fim de subsidiar a formação desses atores para o trabalho com pensamento computacional, junto aos alunos das escolas municipais, foram disponibilizadas as atividades impressas para as professoras supervisoras, para aplicarem nas escolas em que atuam com o auxílio dos pibidianos.

Após tais ações, foi aplicado outro questionário, junto aos bolsistas e às professoras supervisoras, a fim de mapear se fizeram uso das atividades, com o auxílio dos pibidianos e como foi a aprendizagem dos alunos, em relação ao pensamento computacional. Nesse questionário, os participantes da pesquisa puderam elencar as experiências e os desafios encontrados.

Os dados obtidos por meio dos questionários, contendo questões abertas e fechadas, foram analisados seguindo a categorização proposta por (Bardin, 2016), intitulada por blocos semânticos que permitam o agrupamento por afinidade temática, intitulada, na proposta da autora, de Análise de Conteúdo.

(Bardin, 2016) tem configurado a Análise de Conteúdo como um conjunto de técnicas eficaz, que possibilita analisar as comunicações com o intuito de extrair elementos que permitem estabelecer um julgamento, afirmando que "não se trata de um instrumento, mas de um leque de apetrechos; ou seja, com maior rigor, será um único instrumento, mas marcado por uma grande disparidade de formas sendo adaptável a um campo de aplicação muito vasto” (Bardin, 2016, p. 31).

\section{Resultados e Discussão}

Assim, após a aplicação dos questionários descritos na seção anterior, que objetivou mapear se as professoras fizeram uso das atividades, se tiveram o auxílio dos pibidianos e como foi a aprendizagem dos alunos, em relação ao pensamento computacional. Nesse questionário, os participantes da pesquisa puderam elencar as experiências e os desafios encontrados, a análise do Questionário 1, nos trouxe os seguintes dados: 
18 alunos bolsistas (A) e 2 professoras supervisoras (P) participaram da reunião, realizaram as atividades desplugadas e, portanto, responderam ao questionário.

Sobre a "viabilidade da realização das atividades junto aos alunos da educação básica". Por se tratar de uma pergunta não obrigatória, 12 dos 18 alunos bolsistas participantes da pesquisa responderam, sendo que todos (12) afirmaram que "sim", é viável a realização das atividades, porém apenas 10 justificaram a resposta.

Todos esses dados, portanto, foram utilizados na análise. Assim, as respostas dos alunos bolsistas e das professoras supervisoras estão compiladas no Quadro 1, a seguir:

Quadro 1 - Viabilidade da realização das atividades desplugadas na educação básica.

\begin{tabular}{|c|c|}
\hline Categorização & $\begin{array}{c}\text { Percepção dos participantes quanto à viabilidade da realização das } \\
\text { atividades nas escolas em que atuam }\end{array}$ \\
\hline \multirow{4}{*}{ Aprendizagem } & $\begin{array}{l}\text { A1: "Sim, pois isso vai facilitar sua aprendizagem de forma mediadora. E com } \\
\text { essa interação de professor e aluno, o ensino acontece e se realiza." }\end{array}$ \\
\hline & $\begin{array}{l}\text { A2: "Porque esse tipo de atividade ajuda na formação e também ajuda na } \\
\text { agilidade dos alunos." }\end{array}$ \\
\hline & A7: "Importante para a aprendizagem dos alunos." \\
\hline & $\begin{array}{l}\text { A10: "Sim, pois ajuda na formação de um conhecimento mais amplo, } \\
\text { trabalhando várias formas de ensinar." }\end{array}$ \\
\hline \multirow{5}{*}{ Recurso acessível } & A3: "Sim, pois várias vezes não temos Internet disponível." \\
\hline & $\begin{array}{l}\text { P1: "Sim, pois são muito interessantes e estimulam o raciocínio lógico sem uso } \\
\text { de celulares e outros eletrônicos." }\end{array}$ \\
\hline & $\begin{array}{l}\text { P2: "Sim, porque são atividades de fácil impressão, também podem ser } \\
\text { xerocadas caso a instituição não tenha muito recurso financeiro. E para sua } \\
\text { realização são necessários apenas os materiais escolares habituais. Acredito que } \\
\text { seja preciso uma formação para o docente que irá conduzir as atividades, para } \\
\text { estar ciente do método e dos objetivos." }\end{array}$ \\
\hline & $\begin{array}{l}\text { A4: "Sim, é possível inclui-se facilmente no planejamento de aula, pois o } \\
\text { conteúdo assimila-se." }\end{array}$ \\
\hline & A6: "Sim, porque são de fácil aplicação e fácil compreensão." \\
\hline \multirow{4}{*}{$\begin{array}{l}\text { Raciocínio lógico } \\
\text { e resolução de } \\
\text { problemas }\end{array}$} & A5: "Sim é viável pois trabalha o raciocínio lógico." \\
\hline & $\begin{array}{l}\text { P1: "Sim, pois são muito interessantes e estimulam o raciocínio lógico sem uso } \\
\text { de celulares e outros eletrônicos." }\end{array}$ \\
\hline & $\begin{array}{l}\text { A9: "Sim, pois tem como objetivo formar alunos mais criativos e pensantes, } \\
\text { possibilitando a resolver diversos problemas no cotidiano." }\end{array}$ \\
\hline & $\begin{array}{l}\text { A8: "Sim, pois é uma maneira de trabalhar com os alunos e desenvolver a } \\
\text { criatividade e a aprendizagem de forma lúdica, além de possibilitar aos alunos } \\
\text { uma maior autonomia para resolver as situações do dia a dia." }\end{array}$ \\
\hline
\end{tabular}

Fonte: Dados da pesquisa.

Como evidenciado no Quadro 1, as respostas que validam a viabilidade da realização das atividades desplugadas nas escolas foram categorizadas em três grupos: "aprendizagem"; "recurso acessível”; e "raciocínio lógico e resolução de problemas". 
Dos respondentes, quatro alunos se enquadram na categoria "aprendizagem", pois consideraram que utilizar as atividades desplugadas na educação básica iria contribuir e facilitar o aprendizado dos estudantes, além de ajudar em seu processo de formação. Três outros alunos e duas professoras, por sua vez, enquadram-se na categoria "recurso acessível", pois apontaram as atividades desplugadas como um recurso de fácil utilização, por não haver a necessidade do uso de computador conectado à internet, quando a escola não dispõe do recurso. Já os três alunos restantes e a uma professora se enquadram na categoria "raciocínio lógico e resolução de problemas", justificando a viabilidade da realização das atividades, pois elas contribuem para o desenvolvimento do raciocínio lógico e da criatividade dos alunos na resolução de problemas do cotidiano. Ressaltamos que a resposta de P1 atendeu duas categorias, por isso aparece duas vezes na análise.

Em continuidade, no Gráfico 1, a seguir, temos o mapeamento da percepção dos participantes, ao serem questionados quanto ao fato de ter havido aprendizado, após o acesso às informações conceituais sobre PC, apresentadas pela pesquisadora durante a reunião:

Gráfico 1 - Aprendizado sobre o tema após apresentação conceitual.

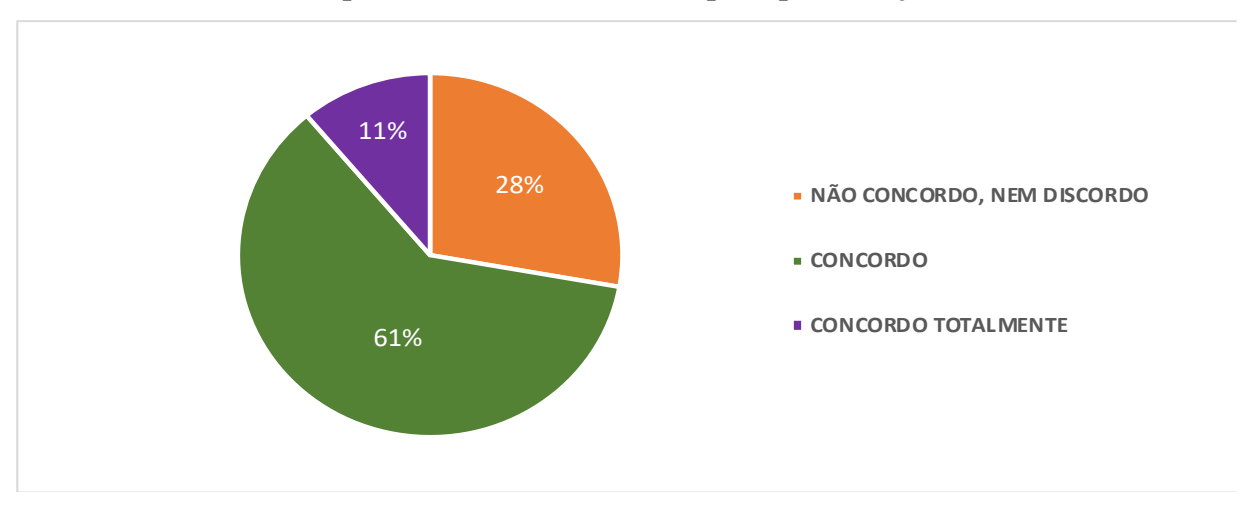

Fonte: Dados da pesquisa.

Os dados indicam que $61 \%$ afirmaram "concordar" que aprenderam sobre o tema; $28 \%$ responderam que "não concordam, nem discordam"; e 11\% assinalaram a opção "concordo totalmente".

Nos meses de outubro a dezembro de 2019, as professoras supervisoras, com o auxílio dos alunos bolsistas do PIBID, aplicaram as atividades desplugadas nas escolas em que lecionam, conforme evidenciado nas Figuras 2 e 3, a seguir: 
Figura 2 - Alunos da Escola Municipal Leonor Maestri de Held realizando as atividades desplugadas.

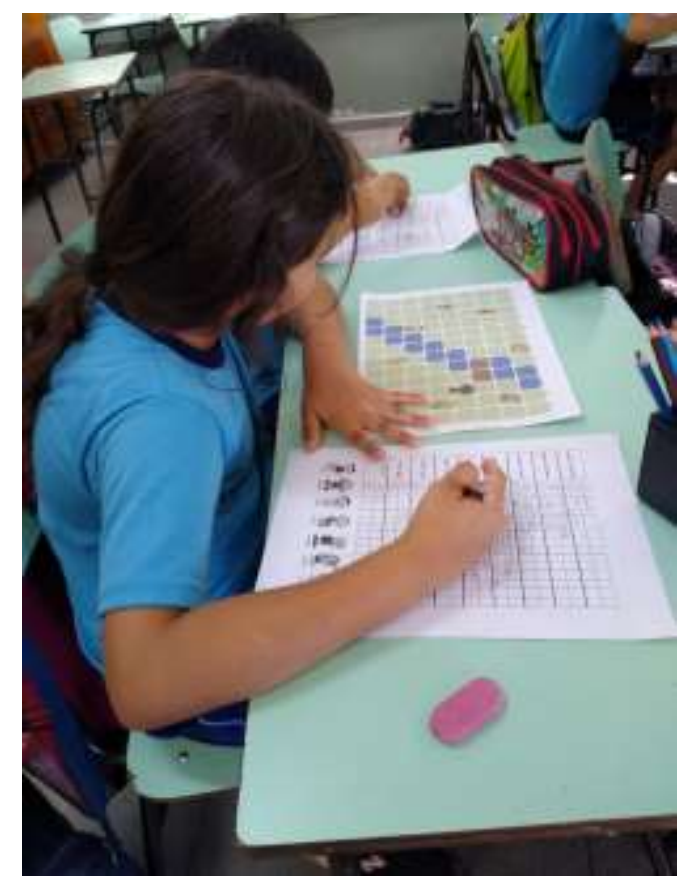

Fonte: Dados da pesquisa.

A P1 teve o auxílio de duas alunas bolsistas, realizando três atividades ("Decomposição", "Caminhos" e "Boneca de Papel”) com uma turma do $2^{\circ}$ ano de 26 alunos entre 7 e 8 anos.

Figura 3 - Alunos da Escola Municipal Professora Maria Tereza Meleiro Amâncio realizando as atividades desplugadas.

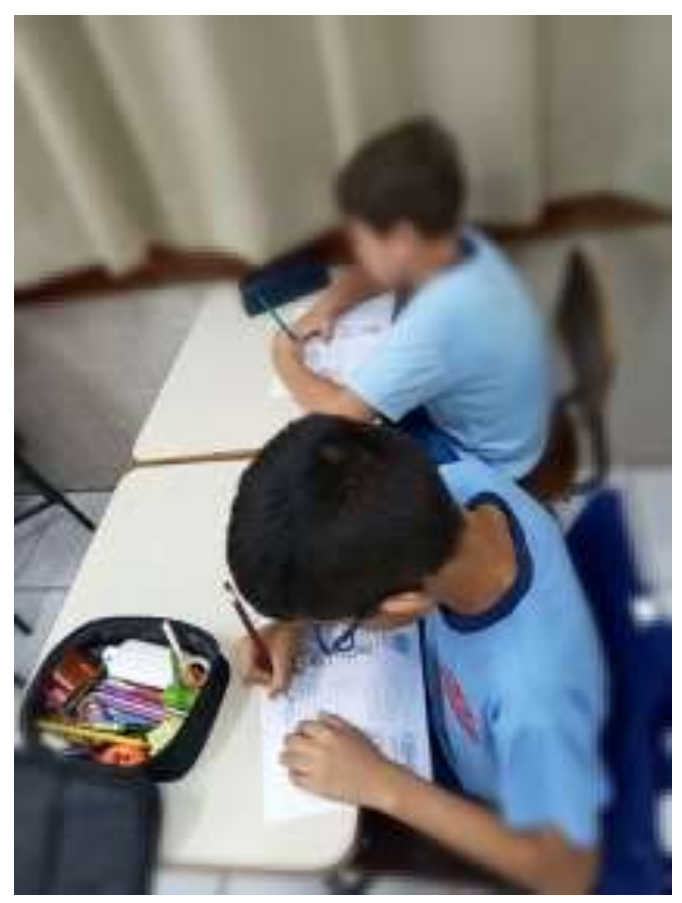

Fonte: Dados da pesquisa.

A P2, por sua vez, teve o auxílio de uma aluna bolsista, e realizou quatro das cinco atividades desplugadas que foram apresentadas e discutidas nas reuniões ("Decomposição", "Caminhos", "Bugs" e "Boneca de Papel"). A professora realizou as atividades com duas turmas do $3^{\circ}$ ano, cada turma possui em média 27 alunos e a idade dos alunos é de 8 a 9 anos. 
Para fins de validação, após esse processo, foi aplicado o segundo instrumento de coleta de dados, o Questionário 2, para verificar as percepções dos participantes quanto à realização das atividades pelos alunos da educação básica, assim como dificuldades encontradas e pontos positivos que foram observados. As duas professoras supervisoras (P) e três alunos bolsistas (A), responderam ao Questionário 2.

Para a análise do Questionário 2, após a finalização da coleta de dados, foram utilizadas duas categorias: dificuldades e pontos positivos. Nos Quadros 2 e 3 elegemos como categoria de análise as "dificuldades" encontradas pelos participantes da pesquisa, ao aplicarem as atividades desplugadas com os alunos da educação básica. E nos Quadros 4 e 5 foi selecionada a categoria de análise "pontos positivos" para proceder a análise.

Quadro 2 - Dificuldades evidenciadas nos alunos da educação básica ao realizarem as atividades.

\begin{tabular}{|c|c|}
\hline Categorização & $\begin{array}{l}\text { Percepção dos participantes quanto ao nível de dificuldade encontrado pelos } \\
\text { alunos ao realizarem as atividades desplugadas }\end{array}$ \\
\hline \multirow{4}{*}{$\begin{array}{l}\text { Dificuldades dos } \\
\text { alunos da } \\
\text { educação básica }\end{array}$} & $\begin{array}{l}\text { A1: "Em sala de aula, ao observar e auxiliar os alunos desenvolverem a atividade, pude } \\
\text { perceber um pouco de dificuldade na organização das etapas, eles sabiam todas, porém } \\
\text { não conseguiam colocá-las em ordem no papel, a outra em relação a traçar o caminho, } \\
\text { muitos se perdiam na contagem." }\end{array}$ \\
\hline & $\begin{array}{l}\text { A2: "O nível de dificuldade foi baixo, os alunos apresentaram em alguns momentos } \\
\text { dificuldades na organização de pensamento e raciocínio. A maioria realizou de maneira } \\
\text { satisfatória." }\end{array}$ \\
\hline & $\begin{array}{l}\text { A3: "Os alunos viram mais dificuldade ao pensar o passo a passo de cada ação, pois } \\
\text { eles colocavam como eles faziam em suas casas e pulavam algumas etapas como } \\
\text { fechar a torneira depois de lavar as mãos." }\end{array}$ \\
\hline & $\begin{array}{l}\text { P2: "As atividades foram aplicadas em duas turmas de } 3^{\circ} \text { ano do ensino fundamental } 1 . \\
\text { As primeiras atividades foram realizadas com pouca dificuldade. A atividade número } 3 \\
\text { "Bugs" foi a que tiveram mais dificuldade na compreensão de como fazer e corrigir o } \\
\text { erro da sequência." }\end{array}$ \\
\hline $\begin{array}{l}\text { Resposta não foi } \\
\text { considerada }\end{array}$ & $\begin{array}{l}\text { P1: "O grau de dificuldade encontrado pelos alunos foram os mais variados: tiveram } \\
\text { alunos que conseguiram resolver com facilidade, outros apresentaram um pouco de } \\
\text { dificuldade, outros porém apresentaram muita dificuldade." }\end{array}$ \\
\hline
\end{tabular}

Fonte: Dados da pesquisa.

A partir da análise das respostas dos participantes da pesquisa no Quadro 2, observamos que a resposta de P1 não especificou quais foram as dificuldades encontradas, portanto foi descartada da análise. Entretanto, A1, A2 e A3 apontaram que os alunos da educação básica apresentaram dificuldades, descritas a seguir. A1 - "organização das etapas” e "colocá-las em ordem no papel". Além disso, destacou que na realização da atividade 2 "caminhos" alguns alunos "se perdiam na contagem". A2 explicou que a dificuldade foi na “organização de pensamento e raciocínio". Enquanto A3 elegeu "pensar o passo a passo de cada ação". Já P2, especificou que na atividade 3 "bugs" os alunos encontraram mais dificuldade, pois para P2 o problema foi "na compreensão de como fazer e corrigir o erro da sequência." 
Quadro 3 - Dificuldades encontradas na aplicação das atividades.

\begin{tabular}{|c|c|}
\hline Categorização & $\begin{array}{c}\begin{array}{l}\text { Percepção dos participantes quanto às dificuldades encontradas na aplicação das } \\
\text { atividades }\end{array} \\
\end{array}$ \\
\hline \multirow{4}{*}{$\begin{array}{l}\text { Dificuldades dos } \\
\text { alunos da } \\
\text { educação básica }\end{array}$} & $\begin{array}{l}\text { A1: "Aplicamos a atividade na sala do } 2^{\circ} \text { ano, junto com a professora regente, a } \\
\text { mesma explicava a atividade e nós auxiliávamos os alunos, alguns tinham dificuldade } \\
\text { para entender, mas quando citávamos exemplos ficava mais compreensível e } \\
\text { conseguiam dar continuidade a atividade. Sobre a aplicação não encontrei muita } \\
\text { dificuldade." }\end{array}$ \\
\hline & $\begin{array}{l}\text { A2: "Dificuldades na organização dos pensamentos, e alguns apresentavam dificuldade } \\
\text { na interpretação do que era proposto nas atividades." }\end{array}$ \\
\hline & A3: "Algumas crianças não entenderam o sentido, e não souberam escrever na ordem." \\
\hline & $\begin{array}{l}\text { P1: "A insegurança de alguns alunos, a dificuldade de compreensão sobre o que estava } \\
\text { sendo aplicado, dificuldade de concentração por parte de alguns alunos." }\end{array}$ \\
\hline Tempo das & $\begin{array}{l}\text { P2: "A maior dificuldade foi o tempo das aulas. Eu tinha uma aula de } 50 \text { minutos com } \\
\text { cada turma. Âs vezes, esse tempo não era suficiente para a explicação, para expor } \\
\text { exemplos de realização (quando era o caso) e a execução da atividade em si." }\end{array}$ \\
\hline
\end{tabular}

Fonte: Dados da pesquisa.

Em relação ao Quadro 3 o objetivo era que os participantes da pesquisa, destacassem quais foram suas dificuldades ao aplicarem as atividades, porém somente P2 respondeu de forma satisfatória, pois expôs o tempo das aulas como maior empecilho para a realização das atividades, inclusive a professora só conseguiu aplicar 4 das 5 atividades entregues. A1 expôs que não encontrou dificuldades na aplicação das atividades.

Retomando a categoria de análise "dificuldades" destacamos os excertos que apontam quais foram: A1 - "dificuldade para entender"; A2 - "dificuldades na organização dos pensamentos" e "dificuldade na interpretação do que era proposto"; A3 - "não entenderam o sentido, e não souberam escrever na ordem"; P1 - "insegurança", "dificuldade de compreensão" e "dificuldade de concentração".

A atividade "Bugs", citada por P2 como a atividade em que os alunos mais tiveram dificuldade, tinha como objetivo exercitar os pilares abstração, decomposição e algoritmos. Porém, ao analisarmos as respostas, podemos concluir que o pilar decomposição foi o que os alunos tiveram mais dificuldade em executar, conforme explica (Liukas, 2015), quando um problema não está decomposto, sua resolução é mais difícil. E uma forma de exercitar a resolução de problemas é decompor em partes menores e mais fáceis de gerenciar. (Brackmann, 2017) explica que esta é uma prática que exige atenção aos detalhes, e é exatamente esse processo que é feito pelos programadores ao desenvolver um programa, dividir um algoritmo em pedaços menores, possibilitando projetar sistemas de grande porte.

Sendo assim, reforçamos a importância de os alunos, desde a educação básica, terem acesso a atividades que exercitem os quatro pilares do pensamento computacional (abstração, decomposição, reconhecimento de padrões e algoritmos), pois estimulam a habilidade de reflexão e solução de problemas.

Ademais, conforme explicam (Brackmann, 2017) e (Valente, 2019), a adoção do PC já faz parte dos currículos de diversos países, tendo em vista que o desenvolvimento de habilidades e competências que o PC promove são essenciais para a vida moderna, independente da área que esses alunos decidirão atuar no futuro.

Diante disso, cabe a nós, pesquisadores da área, apoiarmos os professores que ainda não têm acesso a esses fundamentos em seu processo de formação de forma estruturada, para que os alunos brasileiros tenham as mesmas oportunidades dos alunos de outros países.

A seguir, nos Quadros 4 e 5, foram compilados os “pontos positivos” observados pelos participantes da pesquisa, no que a tange à observação dos alunos da educação básica realizando as atividades e também o "interesse dos licenciandos bolsistas e professoras supervisoras em outras abordagens" que explorem mais os conceitos do pensamento computacional. 
Quadro 4 - Pontos positivos observados durante a realização das atividades.

\begin{tabular}{|c|c|}
\hline Categorização & $\begin{array}{l}\text { Percepção dos participantes quanto aos pontos positivos destacados na } \\
\text { observação dos alunos realizando as atividades desplugadas }\end{array}$ \\
\hline \multirow{5}{*}{ Pontos positivos } & $\begin{array}{l}\text { A1: "Em relação aos pontos positivos destaco aqui a organização para realizar as } \\
\text { atividades e colocá-las em ordem, o pensamento de raciocínio lógico e a combinação } \\
\text { trabalhando as estações do ano." }\end{array}$ \\
\hline & $\begin{array}{l}\text { A2: “A concentração, organização, contagem, pensamento e raciocínio. Os alunos } \\
\text { buscam maneiras para a soluções dos problemas do cotidiano, exemplo qual caminho } \\
\text { irei fazer até chegar em determinado ponto." }\end{array}$ \\
\hline & $\begin{array}{l}\text { A3: "Fazer eles pensarem como realmente acontece, fazer com que eles trabalham } \\
\text { mais os pensamentos" }\end{array}$ \\
\hline & $\begin{array}{l}\text { P1: "Ao realizar as atividades desplugadas posso destacar que essas atividades são } \\
\text { importantes pois exigem atenção e concentração por parte de quem realiza. Além de } \\
\text { serem atividades que despertam interesse por terem desenhos coloridos, por ter recorte } \\
\text { e colagem. Além disso, as crianças precisavam para pensar em soluções para os } \\
\text { exercícios propostos." }\end{array}$ \\
\hline & $\begin{array}{l}\text { P2: "Eles ficaram animados por se tratar de atividades para o desenvolvimento } \\
\text { computacional. As atividades com design mais chamativo, desenhos coloridos, bem } \\
\text { nítidos chamaram mais a atenção dos alunos. O desafio proporcionado pela atividade } \\
\text { também foi um ponto positivo para a maioria dos alunos." }\end{array}$ \\
\hline
\end{tabular}

Fonte: Dados da pesquisa.

Quanto aos pontos positivos, A1 destacou "pensamento de raciocínio lógico"; A2 elegeu “concentração, organização, contagem, pensamento e raciocínio" e A3 destacou como ponto positivo "fazer eles pensarem". P1 também observou a questão relacionada à "concentração" que as atividades exigem, bem como o fato de as atividades serem coloridas, de recorte e colagem, fatores que tendem a despertar o interesse dos alunos. Essa mesma observação foi feita por P2 que destacou "design mais chamativo, desenhos coloridos, bem nítidos chamaram mais a atenção dos alunos".

Da análise das respostas categorizadas como "pontos positivos" entendemos que a proposta da pesquisa atingiu seu objetivo, pois as professoras, assim como os alunos bolsistas, puderam observar, durante a aplicação das atividades, que os alunos da educação básica foram estimulados a exercitarem o raciocínio lógico, pensar de forma estruturada, ter atenção e concentração, para solucionar os desafios propostos.

Tais proposições vêm ao encontro das pesquisas de (Valente, 2019), uma vez que o autor, traz o conceito de pensamento computacional do grupo ISTE/CSTA como um processo de resolução de problemas, que se apoia nas características a seguir:

[...] formulação de problemas de uma forma que permita usar um computador e outras ferramentas para ajudar a resolvê-los; organização lógica e análise de dados; representação de dados por meio de abstrações como modelos e simulações; automação de soluções por meio do pensamento algorítmico (a série de passos ordenados); identificação, análise e implementação de soluções possíveis com o objetivo de alcançar a mais eficiente e efetiva combinação de etapas e recursos; e generalização e transferência desse processo de resolução de problemas para uma ampla variedade de problemas (Valente, 2019, p. 152).

Ainda de acordo com o autor, o grupo defende que as habilidades acima descritas dependem de uma série de atitudes, como "confiança em lidar com a complexidade, persistência em trabalhar com problemas difíceis, tolerância para a ambiguidade e capacidade de lidar com problemas abertos" (ISTE/CSTA, 2011, p. 7).

Isso posto, ao analisar as respostas dos participantes da pesquisa é possível identificar as características da definição do grupo ISTE/CSTA, assim como as atitudes elencadas.

No Quadro 5 identificamos o interesse dos participantes da pesquisa em outras abordagens para o desenvolvimento do PC. 
Quadro 5 - Interesse em outras abordagens para desenvolvimento do PC.

\begin{tabular}{|c|l|}
\hline \multirow{3}{*}{ Categorização } & \multicolumn{1}{c}{$\begin{array}{c}\text { Percepção dos participantes quanto ao interesse em outras abordagens para o } \\
\text { desenvolvimento do pensamento computacional nos alunos }\end{array}$} \\
\hline \multirow{5}{*}{$\begin{array}{c}\text { Interesse em } \\
\text { outras } \\
\text { abordagens }\end{array}$} & $\begin{array}{l}\text { A1: "Sim, acho que seria interessante e bem atrativo para os alunos, porém, devemos } \\
\text { levar em consideração a realidade da escola e dos alunos, pois muitos não tem acesso e } \\
\text { algumas escolas não possui esse recurso." }\end{array}$ \\
\cline { 2 - 3 } & $\begin{array}{l}\text { A2: "Sim gostaria, é bem interessante e atrativo para os alunos, estimulando a } \\
\text { aprendizagem de forma lúdica, possibilitando o aumento ao poder cognitivo, } \\
\text { contribuindo para a produtividade e criatividade. Porém, não há computadores para a } \\
\text { realizações das atividades." }\end{array}$ \\
\cline { 2 - 3 } & $\begin{array}{l}\text { P1: "Sim, porém no momento é inviável em minha escola devido à falta de } \\
\text { computadores." }\end{array}$ \\
\cline { 2 - 3 } & $\begin{array}{l}\text { P2: "Sim, eu gostaria de continuar a aplicação das atividades desplugadas e progredir } \\
\text { para atividades } \text { onlines. Acredito que os alunos ficaram com a expectativa de continuar } \\
\text { as atividades em tablets ou usando o computador. Isso continuaria desenvolvendo o } \\
\text { pensamento lógico, a interpretação, atenção e consequentemente a alfabetização, o } \\
\text { letramento dos alunos, a produção textual, a compreensão de situações matemáticas. } \\
\text { Tudo isso com o incentivo de utilizar as tecnologias digitais também para o } \\
\text { desenvolvimento escolar." }\end{array}$ \\
\cline { 2 - 3 } & \begin{tabular}{l} 
A3: "Mostrando aplicativo que os auxiliam com temas interdisciplinar." \\
\hline
\end{tabular}
\end{tabular}

Fonte: Dados da pesquisa.

O interesse por parte dos respondentes foi justificado conforme os excertos dos enunciados descritos a seguir: A2 “estimulam a aprendizagem de forma lúdica"; P2 - "pensamento lógico, a interpretação, atenção e consequentemente a alfabetização, o letramento dos alunos". A resposta de A3 indicou interesse em abordagens que explorem o uso de aplicativos para trabalhar com os alunos temas interdisciplinares.

A1, A2 e P1, apesar de demonstrarem interesse para a continuidade da realização de atividades de desenvolvimento do pensamento computacional, apontaram que, nas escolas em que atuam, não há recursos tecnológicos disponíveis. Sendo assim, parece-nos que, nessas escolas, a abordagem desplugada continuaria sendo a mais adequada.

Ademais, acrescente-se a isso que sabemos que essa é uma realidade constante em muitas escolas, não apenas no Brasil, mas no mundo, conforme destacado por (Diamandis \& Kotler, 2012), (Geraldes, 2014) e (Brackmann, 2017).

Um exemplo disso é que as pesquisas de (Diamandis \& Kotler, 2012), tratam sobre a realidade de muitas crianças espalhadas pelo mundo, que sequer têm acesso a uma infraestrutura educacional.

Já os estudos de (Geraldes, 2014), explicam que um dos maiores obstáculos enfrentados pelos professores brasileiros para desenvolver um trabalho com tecnologia na escola é a falta de investimento em infraestrutura, com a carência de bons computadores e de internet banda larga em laboratórios bem equipados.

(Brackmann, 2017), por sua vez, justifica a utilização de atividades desplugadas, em face da situação socioeconômica brasileira, como a falta de laboratório de informática e, até mesmo, energia elétrica, em algumas escolas.

Mediante o exposto, acreditamos, também, que o fato de as atividades serem coloridas e trazerem personagens que os alunos conhecem - Turma da Mônica - motivou os alunos a concluírem as atividades, visto serem personagens que fazem parte do conhecimento de mundo deles.

Assim, reforçarmos que as atividades desplugadas, conforme mencionado por (Brackmann, 2017), embora possam não atender aos fundamentos da computação por completo, elas são, sim, no nosso entender, recomendadas para a introdução do pensamento computacional na esfera escolar. 


\section{Considerações Finais}

Este trabalho objetivou verificar as percepções de professores supervisores e alunos bolsistas do PIBID, do município de Londrina-PR, quanto à viabilidade e o nível de dificuldade encontrado em relação à introdução do pensamento computacional (PC) na educação básica, por meio da realização de atividades desplugadas.

Para atender a este objetivo foram organizadas cinco atividades desplugadas, visando à introdução do pensamento computacional para alunos da educação básica, verificamos que esses recursos foram selecionados, conforme apresentação dos sítios que os disponibilizam, sendo as atividades devidamente aplicadas aos participantes da pesquisa. A aplicação das atividades nos permitiu promover uma capacitação, destinada aos alunos bolsistas do PIBID e às professoras supervisoras, a fim de subsidiar a formação desses atores para o trabalho com pensamento computacional.

Sobre o resultado da aplicação dessa capacitação, os dados obtidos por meio dos questionários aplicados nos indicam que, apesar de ser considerado um assunto relevante, ainda é necessário que seja devidamente aprofundado, pois a falta de conhecimento sobre as possibilidades de desenvolvimento da cognição, da criatividade e do lado operacional humano pode ser um fator limitador que tenha como consequência a falta de adoção na esfera escolar.

No que tange à disponibilização das atividades, foi necessário adaptar ao contexto de pesquisa. Assim, as atividades foram fornecidas já devidamente organizadas em cópias, para que tivessem possibilidade de aplicação na escola, conforme solicitado pelas professoras supervisoras.

Retomando as ideias de (Wing, 2006) e (Blikstein, 2008), no sentido de ser papel do professor auxiliar a desmistificar a crença de que o pensamento computacional esteja limitado à codificação, de forma que o professor passe a explorar essas atividades para auxiliar no desenvolvimento dos alunos, adotando a tecnologia como uma ferramenta facilitadora para vir a promover a criatividade e a motivação em sala de aula.

Mediante o exposto, como defendido por (Raabe, et al., 2020), concordamos que todas as abordagens que buscam introduzir o pensamento na educação básica são válidas e se complementam.

Todavia, acreditamos que a primeira abordagem, "construcionismo e letramento computacional", é que deve ser o foco ao introduzir o PC na educação básica, pois nela a computação é trabalhada de forma transversal, podendo ser utilizada em diferentes áreas do conhecimento, enquanto o computador é visto como ferramenta para o aprendizado, sendo assim a ênfase deixa de ser na programação em si, e passa a ser o quanto os estudantes são fluentes e capazes de criar e inovar por meio da tecnologia.

Para também destacarmos a importância da quarta abordagem, "equidade e inclusão", em uma sociedade marcada por desigualdades sociais e constantemente impactada pelos avanços da tecnologia, os estudantes precisam ser preparados não apenas para utilizar essas tecnologias, uma vez que a computação permeia todos os setores, mas os estudantes devem focar em melhora de demandas ou mesmo na produção de soluções ainda não concebidas.

O mapeamento sobre a visão das professoras supervisoras e dos pibidianos sobre a exequibilidade da introdução do pensamento computacional, por meio de atividades desplugadas na escola, apresentou um resultado favorável, no sentido de compreenderem ser possível e relevante. O resultado da aplicação das atividades realizadas pelas professoras supervisoras com auxílio dos bolsistas do PIBID apontou para a efetividade do trabalho com o PC na escola.

Outro ponto relevante observado durante os estudos para essa pesquisa é que a área de ensino ainda se apresenta como um amplo campo de pesquisa para a investigação, aplicação ou mesmo reflexões sobre possibilidades de adoção das atividades que envolvem o pensamento computacional na esfera escolar.

Em pesquisa posterior, em fase de doutoramento, o foco será na aplicabilidade das atividades, junto a rede municipal de Londrina-Pr, podendo ser levado a campo tanto com a continuidade da parceria entre o curso de Pedagogia, por meio do PIBID, como através de um curso de formação para os professores da rede municipal. Outra ação exequível é a criação de um 
produto, na modalidade de e-book, disponibilizado como recurso educacional aberto, no qual os professores podem ter acesso a um referencial teórico e prático, para maior aprofundamento do tema e identificação de novas possibilidades de inserção do pensamento computacional na Educação Básica.

\section{Referências}

Abilio, L. C. (2019). Uberização: do empreendedorismo para o autogerenciamento subordinado. Psicoperspectivas, Valparaiso. 18(3), 41-51. https://dx.doi.org/10.5027/psicoperspectivas-vol18-issue3-fulltext-1674

Bardin, L. (2016). Análise de conteúdo. Edições 70.

Blikstein, P. (2008). O pensamento computacional e a reinvenção do computador na educação. http://www.blikstein.com/paulo/docume nts/online/ol_pensamento_computacional.html.

Brackmann, C. P. (2017). Desenvolvimento do pensamento computacional através de atividades desplugadas na educação básica. (Tese de doutorado). Universidade Federal do Rio Grande do Sul, Porto Alegre, RS.

Brackmann, C. P. (2019). Pensamento Computacional Brasil. http://www.computacional.com.br

Brasil, (2010). Ministerio da Educação. Decreto n. 7.219 de 25/06/2010. Dispõe sobre o Programa Institucional de Bolsa de Iniciação à Docência e dá outras providências. Brasília.

Brasil, (2017). Ministério da Educação. Base Nacional Comum Curricular: educação é a base. Brasília.

Costa, L. V. (2010). A relação entre a percepção de sucesso na carreira e o comprometimento organizacional: um estudo entre professores de universidades privadas selecionadas da Grande São Paulo. (Tese de doutorado). Universidade de São Paulo, São Paulo, SP.

Diamandis, P. H., \& Kotler, S. (2012). Abundância: o futuro é melhor do que você imagina. HSM Editora.

Disessa, A. (2001). Changing minds: computers, learning, and literacy. Paperback edition. MIT Press.

França, R. S.; Silva, W. C., \& Amaral, H. J. C. (2012). Ensino de Ciência da Computação na educação básica: experiências, desafios e possibilidades. Anais do XX WEI (Workshop sobre Educação em Computação), Curitiba.

Garlet, D., Bigolin, N. M. \& Silveira, S. R. (2016). Uma proposta para o ensino de programação de computadores na educação básica. Santa Maria. https://www.ufsm.br/cursos/graduacao/sistemas-de-informacao-fw/wp-content/uploads/sites/333/2018/11/DanielaGarlet.pdf.

Geraldes, W. B. (2014). Programar é bom para as crianças? Uma visão crítica sobre o ensino de programação nas escolas. Texto Livre, Goiás, 7(2). http://www.periodicos.letras.ufmg.br/index.php/textolivre/article/view/6143.

Gil, A. C. (2002). Como elaborar projetos de pesquisa. (4th ed.) São Paulo: Atlas.

Iste/Csta. (2011). Computational Thinking Teacher Resource. (2th ed.). www.iste.org/docs/ct-documents/ct-teacher-resources_2ed-pdf.pdf?sfvrsn=2.

Liukas, L. (2015). Hello Ruby: adventures in coding. Feiwel\&Friends.

Minayo, M. C. S. (2002). Pesquisa social: teoria, método e criatividade. (21th ed.) Vozes.

Raabe, A. L. A. et al. (2015). Recomendações para Introdução do Pensamento Computacional na Educação Básica. Anais do Congresso Anual da SBC. Porto Alegre: SBC, 1, 15-25.

Raabe, A., Zorzo, A. F., \& Blikstein, P. (Orgs.) (2020). Computação na educação básica: fundamentos e experiências. Penso.

Valente, J. A. (2016). Integração do pensamento computacional no currículo da educação básica: diferentes estratégias usadas e questões de formação de professores e avaliação do aluno. Revista e-Curriculum, São Paulo, 14(3), 864-897. http://revistas.pucsp.br/index.php/curriculum/article/view/29051.

Valente, J. A. (2019). Pensamento computacional, letramento computacional ou competência digital? Novos desafios da educação. Revista Educação e Cultura Contemporânea, 16(43), 147-168.

Wing, J. (2006). Computational thinking. Communications of the ACM, 49(3), 33. 